\title{
Abdominal Pregnancy at the University College H ospital, Ibadan: A Ten-Year Review
}

\author{
OA A yinde, CO A imakhu, OA A deyanju and A 0 Omigbodun
}

\begin{abstract}
ABST RACT
Fourteen cases of abdominal pregnancy managed at the U niversity College H ospital, I badan, $\mathrm{N}$ igeria, over a tenyear period (J anuary 1994 to D ecember 2003) were reviewed. The incidence ratio of abdominal pregnancy was one in 654 deliveries. It accounted for $4.3 \%$ of ecto pic pregnancies. A ge range was 20 to 43 years; $63.4 \%$ of the patients were unemployed and $50 \%$ were nullipara. Pre-operative diagnosis was possible only in half of the cases. 0 nly two patients with advanced pregnancies and livefetuses (14.3\%) were allowed to have conservative management while the others had immediate laparotomy. Live birth rate was $7.1 \%$, but overall fetal survival rate was $0 \%$. Fetal malformations were common, with talipes equinovarus and jaw abnormalities occurring in $49.2 \%$ and $14.3 \%$ respectively. Twelve patients (85.7\%) who had complete removal of the placenta, though lost more blood, had better outcomethan those with placenta left in-situ. The casefatality ratewas 7.1\%. (A fr ) R eprod $\mathrm{H}$ ealth 2005; 9[1]:
\end{abstract} 123-127)

\section{RÉ SUMÉ}

Grossesse abdominale au Centre H ospitalier U niversitaire d'I badan: Compte rendu couvrant dix ans. L'étude passe en revue quartorze cas de grossesse abdominale traités au Centre H ospitalier U niversitaire d'I badan, N igéria, au cours d'une période de dix ans (janvier 1994 au décembre 2003). L'indice de fréquence de grossesse abdominale était 1 sur 654 accouchements. E lle était responsable de $4,3 \%$ de grossesses éctopiques. L'âge variait entre 20 et 43 ans; $63,4 \%$ des patients étaient en chômage et 50\% étaient des nullipares. Le diagnostique préopératoire n'était possible que chez la moitié des cas. D eux malades dont les grossesses étaient avancées et qui avaient de foetus vivants (14,3\%) ont été autorisées d'avoir un traitement conservateur alors que les autres ont subi la laparotomie. Le taux de naissance vivante était de $7,1 \%$, mais le taux global de survie de foetus était de $0 \%$. Les malformations de foetus étaient communes alors que se présentaient le pied bot varus équin et les anormalitiés de la mâchoirechez $49,2 \%$ et $14,3 \%$ respectivement. D ouzemalades (85,7\%) dont les placentas ont été complètement enlevés ont perdu davantage de sang, ont eu un meilleur résultat que celle dont les placentas sont restés in situ. Le taux de cas de fatalité était de 7,1\%. (R ev A fr SantéR eprod 2005; 9[1]: 123-127)

KEY WORDS: A bdomen, pregnancy, laparotomy, diagnosis, N igeria

$D$ epartment of $\mathrm{O}$ bstetrics and $\mathrm{G}$ ynaecology, U niversity $\mathrm{C}$ ollege $\mathrm{H}$ ospital, I badan, $\mathrm{N}$ igeria.

Correspondence: D r O A A A yinde, D epartment of O bstetrics and $G$ ynaecology, U niversity C ollege $\mathrm{H}$ ospital, I badan, $N$ igeria. E-mail: sola_ayinde@ yahoo.com 


\section{Introduction}

Abdominal pregnancy is a very rare type of ectopic pregnancy but is rather a very serious condition associated with significant maternal and perinatal morbidity and mortality. ${ }^{1,2}$ It may be primary or secondary to tubal pregnancy that aborts through the fimbrial end of the fallopian tube, implanting in the peritoneal cavity. ${ }^{3}$ Its diagnosis is difficult to make clinically and with conventional imaging techniques, making stateof-the-art diagnostic methods such as Doppler velocimetry very necessary sometimes. ${ }^{4,5}$ In spite of this, many cases are not correctly diagnosed until during laparotomy. ${ }^{6}$ A part from this, management remains controversial especially in advanced cases; you have to choose between immediate laparotomy and conservative management as well as removal of the placenta and leaving it in situ. ${ }^{1,2,5}$ Furthermore, there is paucity of data on abdominal pregnancy in $\mathrm{N}$ igeria; only few case series and scattered case reports are available, with little information on overall clinical picture, management protocols and outcome. ${ }^{1,7,8}$

The objective of this study was to review the modes of presentation, diagnosis, modalities of treatment and the overall outcome of cases of abdominal pregnancy seen at the U niversity College H ospital, I badan, N igeria.

\section{Patients and $M$ ethods}

H ospital records of patients diagnosed with abdominal pregnancy at the University College H ospital, I badan, between January 1994 and December 2003 were reviewed. Sociodemographic characteristics of the identified cases, mode of diagnosis, findings at laparotomy, and fetal and maternal outcomes were studied. $D$ ata were fed into a computer using E PI IN FO 2000 statistical package (Centre for D isease Control, A tlanta, USA ). A nalysis was carried out by generation of frequency tables. Further analysis was by the Student's t-test for differences in continuous variables

\section{Results}

Fourteen cases of abdominal pregnancy were managed at the University College Hospital, I badan, $\mathrm{N}$ igeria, over a ten-year period (J anuary 1994 and December 2003). D uring the same period, the total number of deliveries conducted at the hospital was 9,149 . This gives an incidence ratio of one abdominal pregnancy per 654 deliveries. The total number of ectopic pregnancies seen during the period under review was 323. Therefore, abdominal pregnancy accounted for $4.3 \%$ of ectopic pregnancies.

Patients with abdominal pregnancy were between 20 and 43 years old, with a mean age of $28.5( \pm 7.0)$ years. $N$ ine $(64.3 \%)$ of the patients were unemployed, $2(14.3 \%)$ each were traders and domestic servants, while the remaining patient was a seamstress. Ten $(71.4 \%)$ of them were married and 4 (28.6\%) were single. Their parity ranged from zero to four. Seven $(50 \%)$ of the patients were nullipara, $4(28.6 \%)$ were primipara, while the remaining $3(21.4 \%)$ were multipara. G estational age at diagnosis varied from 8 to 40 weeks, with two of the cases diagnosed at term. M ean gestational age was 22.9 $( \pm 14.4)$ weeks. Pre-operative diagnosis of abdominal pregnancy with ultrasonography was possible in $7(50.0 \%)$ patients; the others were diagnosed at laparotomy. Seven $(50 \%)$ of the cases had previous history of abortion, but only $2(14.3 \%)$ had a preceding history of infertility. Twelve $(85.7 \%)$ of the patients had anaemia at the time of diagnosis; out of which $5(35.7 \%)$ had mild anaemia (PCV 27-29\%), 7 (50.0\%) had moderate anaemia (PCV 19-26), while the remaining 2 (14.3\%) had severe anaemia (PCV $18 \%$ and below). The clinical presentation of the patients with abdominal pregnancy is as shown in Table 1.

Twelve $(85.7 \%)$ of the patients had immediate laparotomy; two (14.3\%) of them who were diagnosed in late mid-trimester (between 24 and 26 weeks) with live fetuses were offered conservative management. This entailed

A frican Journal of Reproductive $\mathrm{H}$ ealth $\mathrm{V}$ ol. $9 \mathrm{~N} 0.1 \mathrm{~A}$ pril 2005 
bed rest, fortnightly ultrasound biometry and all round the clock preparedness for emergency laparotomy. Conservative management was terminated in one of the patients due to sudden fetal demise at 30 weeks gestation. The other patient had elective laparotomy at about 34 weeks gestation, by which time fetal lung maturity was expected.

$\mathrm{N}$ ine $(57.9 \%)$ patients had haemoperitoneum, eleven $(78.6 \%)$ needed peri-operative transfusion, while one $(7.1 \%)$ of the fetuses was delivered alive. The baby however suffered early neonatal death. Therefore, live birth rate was $7.1 \%$, while overall fetal survival rate in the study was $0 \%$. O bvious abnormalities were observed in six of the fetuses; all (42.9\%) of which had talipes equinovarus, while $2(14.3 \%)$ had jaw malformations.

The various sites of placental attachment in the cases seen are illustrated in Table 2 . Complete removal of the placenta was possible in 12 $(85.7 \%)$ cases. H aemostasis was secured at the

Table 1 Clinical Presentation of Patients with Abdominal Pregnancy

\begin{tabular}{lcr}
\hline Clinical presentation & N umber of patients & $\%$ \\
\hline A menorrhoea & 12 & 85.7 \\
A bdominal pain & 14 & 100.0 \\
Vaginal bleeding & 7 & 50.0 \\
Excessive vomiting & 2 & 14.3 \\
A bdominal distension & 7 & 50.0 \\
Abdominal tenderness & 12 & 85.7 \\
Abdominal mass separate from the uterus & 1 & 7.1 \\
D etectable fetal heart tone & 2 & 14.3 \\
\hline
\end{tabular}

Table 2 Sites of Placental Attachment

\begin{tabular}{lcr}
\hline Site of attachment & N umber & $\%$ \\
\hline Bowels and omentum & 7 & 50.0 \\
Pouch of D ouglas & 3 & 21.5 \\
Broad ligament & 1 & 7.1 \\
Uterine wall & 1 & 7.1 \\
Posterior abdominal wall and great vessels & 2 & 14.3 \\
Total & 14 & 100.0 \\
\hline
\end{tabular}

Table 3 Intra-Operative Management of Placenta and Associated Blood Loss

\begin{tabular}{lcccc}
\hline Fate of placenta & N umber & $\%$ & Mean blood loss/ L & Standard deviation $/ L$ \\
\hline Left in situ & 2 & 14.3 & 0.25 & 0.07 \\
D elivered & 12 & 85.7 & 1.10 & 0.55 \\
\hline
\end{tabular}

$t=1.365 ; p=0.045$ 


\section{A frican Journal of R eproductive $\mathrm{H}$ ealth}

placental bed in all cases through under-running stitches and sometimes application of surgicel. The placentae had to be left in situ in two cases where the attachment was to the posterior abdominal wall, with adherence to the major vessels. The placenta was left behind in one out of the nine operations performed by consultant gynaecologists and one out of five cases operated by senior residents. The mean operative blood loss was significantly higher with removal of the placenta, compared to leaving it in situ, as shown in Table 3. E leven out of the twelve patients in whom the placentae were removed required perioperative blood transfusion while this was not necessary in either of the two patients with placentae left in situ. The units of blood transfused ranged from two to four, with mean 2.8. It is, however, worthy of note that leaving the placenta in situ without adjuvant chemotherapy, as done in this series, was associated with spontaneous detachment and severe post-operative complications in the affected two cases. O ne of the patients had post-operative wound infection and dehiscence with extrusion of the placenta through the wound. This was the only case complicated by wound sepsis. The other had severe secondary (intra-abdominal) haemorrhage resulting in death. It was the only case of maternal mortality recorded in the series. Hence, the case fatality rate of abdominal pregnancy in this study was one in $14(7.1 \%)$. However, the commonest postoperative complication in the series was pyrexia, which occurred in $5(35.7 \%)$ patients.

\section{Discussion}

Abdominal pregnancy remains a very rare occurrence. Bonfante et $\left.a\right|^{6}$ reported the incidence of one in 3,372 to 10,200 deliveries, accounting for $4.0 \%$ of ectopic pregnancies and women of low socio-economic class most commonly affected. The incidence of the condition in our series was one in 650 deliveries and it accounted for $4.3 \%$ of ectopic pregnancies. Similarly, majority $(64.3 \%)$ of the patients were unemployed. A nother common finding among the patients was low parity; $78.6 \%$ of them were nullipara and primipara, with the former contributing $42.9 \%$. This is similar to $36.3 \%$ primipara reported in a similar study by A djahoto et al. ${ }^{1}$

The clinical presentation of abdominal pregnancy observed in this study is similar to that of ectopic pregnancy in general. However, recurrent abdominal pain in a pregnant woman, especially in the presence of an abdominal mass separate from the uterus or abnormal fetal lie, may be suggestive of abdominal pregnancy. This should prompt comprehensive abdominal ultrasound examination. This study further illustrates continuing difficulty in diagnosing the condition. O nly $50.0 \%$ of the patients had preoperative diagnosis based on ultrasound examination, which is similar to $42.9 \%$ preoperative diagnosis rate reported by Mekki et al. ${ }^{2}$

In many cases the diagnosis of abdominal pregnancy is an indication for emergency exploratory laparotomy. ${ }^{9} \mathrm{H}$ owever, in advanced cases diagnosed after attainment of fetal viability, conservative management may be a feasible alternative to immediate laparotomy, provided the woman is fully informed of the attendant risks and close surveillance of the pregnancy is undertaken. ${ }^{5,10}$ The unfavourable outcomes of patients managed conservatively in the study raise serious doubts about the desirability of this form of management, although the small number of patients involved makes it difficult to draw a valid conclusion on the observation. Thelow live birth rate in this study is similar to what has been reported in previous studies. ${ }^{1,6,7}$

Complete excision of the placenta was possible in majority $(85.7 \%)$ of the patients. A djahoto et $a^{1}$ and M ekki et al ${ }^{2}$ reported complete placental excision in $71.4-90.9 \%$ of cases, although they were associated with greater haemorrhage. $\mathrm{H}$ aemostasis at the placental bed was secured in patients studied with under-running 
stitches where necessary. An alternative to this is surgical gauze packing used by $\mathrm{F}$ arag et al. ${ }^{11}$ H owever, mean blood loss and blood transfusion rate in this study were higher among those patients who had placental excision. 0 verall, the findings in this study suggest that placental excision may be wise when feasible. This is in contrast to the findings by Mekki et al, ${ }^{2}$ which showed better outcome with leaving the placenta in situ. $\mathrm{O}$ the other hand, it is possible that the unfavourable outcome resulting from leaving the placenta in situ may be related to implantation on potentially dangerous sites such as the posterior abdominal wall and the major vessels as observed in this study.

A surprisingly low case fatality $(7.1 \%)$ of abdominal pregnancy was found. This is at variance with the very high figures reported in most literature ${ }^{2}$ but compares favourably with $15.3 \%$ reported from a similar study in $G$ hana, within the same West A frican coast.

\section{References}

1. Adjahoto EOA, Attignon A and Kodonou K. Abdominal pregnancy: study of a series of 11 cases. R ey M ed SuisseR omande 2002; 122(1): 39-42.

2. M ekki $Y, G$ illes J $M, M$ endez $L$ and $O$ 'Sullivan $M J$. Abdominal pregnancy: to remove or not to remove the placenta. Prim $\mathrm{C}$ are $\mathrm{U}$ pdate $\mathrm{Ob} \mathrm{G}$ yns 1998; 5(4): 192.

3. Ozdemir I, Demirci F, Yucel 0 and Alper $M$. Primary omental pregnancy presenting with hemorrhagic shock. A case report. $G$ ynecol 0 bstet Invest 2003; 55(2): 116- 118.
4. Jazayeri A, D avis TA and Contreras D N. D iagnosis and management of abdominal pregnancy. A case report. J Reprod M ed 2002; 47(12): 1047-49.

5. VarmaR, M ascarenhas $L$ and James D. Successful outcome of advanced abdominal pregnancy with exclusive omental insertion. U ltrasound 0 bstet $G$ ynecol 2003; 21(2): 192-194.

6. Bonfante Ramirez E, B olanos A ncona R, Simon Pereyra $L$, Juarez $G$ arcia $L$ and $G$ arcia-Benitez $C Q$. Abdominal pregnancy, institutional experience. $G$ inecol 0 bstet M ex 1998; 66: 287-289.

7. O pare-Addo HS and D eganus S. Advanced abdominal pregnancy: a study of 13 consecutive cases seen in 1993 and 1994 at K omfo A nokye Teaching H ospital, K umasi, G hana. A fr J R eprod $H$ ealth 2000; 4(1): 28-39.

8. Ravera M and Cocozza E. Late abdominal pregnancy: expectant management with survival of the infant. C lin E xp 0 bstet $G$ ynecol 1997; 24(2): 107-108.

9. Pricop M, Tomosoiu C, Feurdean M, G afencu C, M usca S, Slatineanu S and D aniil C. A bdominal pregnancy. Case report, review of the literature. Rev M ed C hir Soc M ed N at I asi 2000; 104(2): 139142.

10. G arcia-Benitez CQ , L ira PlascenciaJ and D uenas Riano JJ.Conservative management of secondary ectopic abdominal pregnancy. Case report with literature review. $G$ inecol 0 bstet M ex 2003; 71: 181186.

11. Farag GE , Ray S and Ferguson A. Surgical packing as a means of controlling massive haemorrhage in association with advanced abdominal pregnancy. E ur J 0 bstet $G$ ynecol R eprod Biol 2003; 109(1): 106107. 